\title{
Selective Sorption of Organic Molecules by the Flexible Porous Hybrid Metal-Organic Framework MIL-53(Fe) Controlled by Various Host-Guest Interactions
}

\author{
Franck Millange, ${ }^{*},{ }^{\dagger}$ Nathalie Guillou ${ }^{\dagger}$ Manuela E. Medina, ${ }^{\dagger}$ Gérard Férey, ${ }^{\dagger}$ \\ Abel Carlin-Sinclair, ${ }^{\star}$ Kathryn M. Golden, ${ }^{\S}$ and Richard I. Walton ${ }^{\S}$ \\ ${ }^{\dagger}$ Institut Lavoisier (CNRS UMR 8180), Université de Versailles, 78035 Versailles, France, \\ 'Département de Chimie, Université de Versailles, 78035 Versailles, France, and \\ ${ }^{\S}$ Department of Chemistry, University of Warwick, Coventry, CV4 7AL, U.K.
}

Received March 25, 2010. Revised Manuscript Received June 3, 2010

\begin{abstract}
The structures of four iron(III) carboxylate materials with the MIL-53 structure and the guest molecules water, pyridine, or 2,6-dimethylpyridine (2,6-lutidine) have been solved and refined from high-resolution powder X-ray diffraction data. These materials have porous structures constructed from infinite chains of trans-corner-shared $\left\{\mathrm{FeO}_{4}(\mathrm{OH}, \mathrm{F})_{2}\right\}$ octahedra cross-linked by benzenedicarboxylate ligands. With pyridine, the unit cell is partially expanded with respect to the hydrated phase, with hydrogen bonds between $\mathrm{N}$ donors and $\mathrm{OH}$ framework atoms, whereas with lutidine, water is co-sorbed to give a fully expanded version of the MIL-53(Fe) structure in which water molecules bridge the $\mathrm{N}$ donors of the organic molecule and the framework $\mathrm{OH}$ groups by hydrogen bonding. Careful dehydration of MIL-53(Fe)[2,6-lutidine, $\left.\mathrm{H}_{2} \mathrm{O}\right]$ provides a new material, MIL53(Fe)[2,6-lutidine $\left.{ }_{0.5}\right]$, with an intermediate unit cell volume: in this case no host-guest hydrogen bonds are formed. Time-resolved in situ energy-dispersive X-ray diffraction shows that when exposed to an aqueous mixture of pyridine and 2,6-lutidine the hydrated MIL-53(Fe) takes up both guest molecules initially to give two distinct phases, but the ultimate product is only MIL-53(Fe)[2,6lutidine, $\left.\mathrm{H}_{2} \mathrm{O}\right]$.
\end{abstract}

\section{Introduction}

Although the established uses of the microporous zeolites and related inorganic analogues in molecular sieving, shape-selective catalysis, and ion exchange have been developed over the past 60 years and are very well documented, ${ }^{1}$ the recent preparation of metal-organic framework (MOF) materials has offered significant new prospects in the properties and applications of porous materials. ${ }^{2}$ This is because both their synthesis and structural chemistry allow for tuning of properties in a more subtle way than has been possible with the purely inorganic frameworks of traditional porous materials. In terms of synthesis, it is in theory possible to select a metal that has some preferred coordination geometry or reactivity and combine it with an organic ligand with chosen connectivity or functionality to crystallize an extended framework structure that has topology, porosity, and

\footnotetext{
*To whom correspondence should be addressed. E-mail: franck.millange@ uvsq.fr.

(1) For recent reviews of current progress of research in zeolite materials and their analogues see: (a) Wight, P.A. Microporous Framework Solids; Royal Society of Chemistry: Cambridge, 2008. (b) Chemistry of Zeolites and Related Porous Materials; Xu, R.; Peng, W.; Yu, J.; Huo, Q.; Chen, J., Eds.; Wiley \& Sons (Asia): Singapore, 2007; (c) Introduction to Zeolite Science and Practise, 3rd revised ed.; Cejka, J., van Bekkum, H., Corma, A., Schuth, F., Eds.; Studies in Surface Science and Catalysis; Elsevier: Amsterdam, 2007; Vol. 168.
}

(2) Férey, G. Chem. Soc. Rev. 2008, 37, 191. reactivity tuned for a particular function. ${ }^{3}$ The porosity in MOFs ranges from the microporous to the mesoporous, and their functionality arises from various chemical facets, including the use of chiral ligands to give chiral solid frameworks, ${ }^{4,5}$ ligands containing reactive groups for catalysis, ${ }^{6}$ or ligands designed with a particular binding affinity for particular sorbates. ${ }^{7,8}$ In terms of their structural chemistry and properties, MOFs offer distinct new opportunities in practical applications, which may be advantageous over the zeolites: for example, their hybrid frameworks can be readily functionalized post-synthesis to tune their reactivity, ${ }^{9,10}$ and their structures may show extreme flexibility in the solid-state, involving atom displacements of up to tens of Ångströms, ${ }^{11-13}$ which

(3) Long, J. R.; Yaghi, O. M. Chem. Soc. Rev. 2009, 38, 1213.

(4) Bradshaw, D.; Claridge, J. B.; Cussen, E. J.; Prior, T. J.; Rosseinsky, M. J. Acc. Chem. Res. 2005, 38, 273.

(5) Livage, C.; Guillou, N.; Rabu, P.; Pattison, P.; Marrot, J.; Férey, G. Chem. Commun. 2009, 4551.

(6) Farrusseng, D.; Aguado, S.; Pinel, C. Angew. Chem., Int. Ed. 2009, 48,7502 .

(7) Rowsell, J. L. C.; Yaghi, O. M. Angew. Chem., Int. Ed. 2005, 44, 4670.

(8) Li, Q.; Zhang, W.; Miljanic, O. S.; Sue, C. H.; Zhao, Y. L.; Liu, L.; Knobler, C. B.; Stoddart, J. F.; Yaghi, O. M. Science 2009, 325, 855.

(9) Fischer, R. A.; Woll, C. Angew. Chem. Int Ed 2008, 47, 8164

(10) Tanabe, K. K.; Cohen, S. M. Angew. Chem., Int. Ed. 2009, $48,7424$.

(11) Kitagawa, S.; Uemura, K. Chem. Soc. Rev. 2005, 34, 109.

(12) Serre, C.; Mellot-Draznieks, C.; Surblé, S.; Audebrand, N.; Filinchuk, Y.; Férey, G. Science 2007, 315, 1828.

(13) Férey, G.; Serre, C. Chem. Soc. Rev. 2009, 38, 1380. 
Table 1. Unit Cell Data for the Four MIL-53 Materials Studied, Resulting from the Rietveld Refinement of Their Structures

\begin{tabular}{lcccc}
\hline & MIL-53(Fe)[H $\left.\mathrm{H}_{2} \mathrm{O}\right]^{a}$ & ${\text { MIL-53(Fe)[pyridine }]^{b}}$ & ${\left.\text { MIL-53(Fe)[2,6-lutidine, } \mathrm{H}_{2} \mathrm{O}\right]^{c}}^{c}$ & MIL-53(Fe)[2,6-lutidine $\left._{0.5}\right]^{b}$ \\
\hline$a / \AA$ & $21.12992(9)$ & $19.2034(2)$ & $15.9624(1)$ & $19.8910(5)$ \\
$b / \AA$ & $7.64271(6)$ & $11.1758(1)$ & $14.3920(1)$ & $9.2980(4)$ \\
$c / \AA$ & $6.83058(7)$ & $6.88903(6)$ & $6.93508(4)$ & $6.8771(3)$ \\
$\beta /$ deg & $114.9352(4)$ & $109.0041(6)$ & $1593.20(2)$ & $107.482(2)$ \\
volume $/ \AA^{3}$ & $1000.25(2)$ & $1397.89(3)$ & Imcm & $1213.14(8)$ \\
$S . G$. & $C 2 / c$ & $C 2 / c$ & 744 & $62 / c$ \\
$M_{20}$ & 435 & 250 & 7.218 & 65 \\
$R_{\mathrm{B}} / \%$ & 5.362 & 4.751 & $7.910,10.520$ & 4.333 \\
$R_{\mathrm{P}}, R_{\mathrm{WP}} / \%$ & $6.732,8.103$ & $5.349,7.000$ & $7.655,9.918$
\end{tabular}

${ }^{a}$ Closed form. ${ }^{b}$ Half-open form. ${ }^{c}$ Open form, as defined in reference 24.

potentially may find use in tunable molecular sieves. In fact, now industrial applications of MOFs are beginning to be explored. ${ }^{14}$

This paper is concerned with the structural flexibility of one particular MOF material, an iron(III) terephthalate with the MIL-53 structure type. ${ }^{15-17}$ The MIL-53 structure is made up of infinite inorganic chains, consisting of trans-corner-shared $\left\{\mathrm{MO}_{4}(\mathrm{OH}, \mathrm{F})_{2}\right\}$ octahedra, cross-linked by bis-bidentate terephthalate (1,4-benzenedicarboxylate) linkers, as will be illustrated in the figures below. This gives an open-framework structure with lozenge-shaped channels running parallel to the inorganic chains. The dimensions of the channels are very dependent on the presence of guest molecules in the structure, and a remarkable "breathing effect" has been observed upon the introduction or removal of a variety of extra-framework species, involving an opening of the lozenge-shaped channels to give a unit-cell expansion of up to $\sim 60 \%{ }^{13}$ This expansion is reversible, and crystallinity is maintained throughout. Guest molecules that have shown this effect include $\mathrm{CO}_{2}, \mathrm{CH}_{4}, \mathrm{H}_{2} \mathrm{~S}$, and a variety of organic species. ${ }^{18-29}$ These molecules are all of relevance for

(14) Czaja, A. U.; Trukhan, N.; Müller, U. Chem. Soc. Rev. 2009, 38, 1284.

(15) Millange, F.; Serre, C.; Férey, G. Chem. Commun. 2002822

(16) Whitfield, T. R.; Wang, X.; Liu, L.; Jacobson, A. J. Solid State Sci. 2005, 7, 1096.

(17) Millange, F.; Guillou, N.; Walton, R. I.; Grenèche, J.; Margiolaki, I.; Férey, G. Chem. Commun. 2008, 4732.

(18) Serre, C.; Millange, F.; Thouvenot, C.; Nogues, M.; Marsolier, G.; Louer, D.; Férey, G. J. Am. Chem. Soc. 2002, 124, 13519.

(19) Férey, G.; Latroche, M.; Serre, C.; Millange, F.; Loiseau, T.; Percheron-Guegan, A. Chem. Commun. 2003, 2976.

(20) Bourrelly, S.; Llewellyn, P. L.; Serre, C.; Millange, F.; Loiseau, T.; Férey, G. J. Am. Chem. Soc. 2005, 127, 13519.

(21) Serre, C.; Bourrelly, S.; Vimont, A.; Ramsahye, N. A.; Maurin, G.; Llewellyn, P. L.; Daturi, M.; Filinchuk, Y.; Leynaud, O.; Barnes, P.; Ferey, G. Adv. Mater. 2007, 19, 2246.

(22) Llewellyn, P. L.; Maurin, G.; Devic, T.; Loera-Serna, S.; Rosenbach, N.; Serre, C.; Bourrelly, S.; Horcajada, P.; Filinchuk, Y.; Ferey, G. J. Am. Chem. Soc. 2008, 130, 12808.

(23) Alaerts, L.; Maes, M.; Giebeler, L.; Jacobs, P. A.; Martens, J. A.; Denayer, J. F. M.; Kirschhock, C. E. A.; De Vos, D. E. J. Am. Chem. Soc. 2008, 130, 14170.

(24) Millange, F.; Serre, C.; Guillou, N.; Ferey, G.; Walton, R. I. Angew. Chem., Int. Ed. 2008, 47, 4100.

(25) Hamon, L.; Serre, C.; Devic, T.; Loiseau, T.; Millange, F.; Ferey, G.; De Weireld, G. J. Am. Chem. Soc. 2009, 131, 8775.

(26) Finsy, V.; Kirschhock, C. E. A.; Vedts, G.; Maes, M.; Alaerts, L.; De Vos, D. E.; Baron, G. V.; Denayer, J. F. M. Chem.-Eur. J. 2009, 15,7724

(27) Finsy, V.; Ma, L.; Alaerts, L.; De Vos, D. E.; Baron, G. V.; Denayer, J. F. M. Microporous Mesoporous Mater. 2009, 120, 221.

(28) Meilikhov, M.; Yusenko, K.; Fischer, R. A. Dalton Trans. 2009, 600.

(29) Alaerts, L.; Maes, M.; van der Veen, M. A.; Jacobs, P. A.; De Vos, D. E. Phys. Chem. Chem. Phys. 2009, 11, 2903.

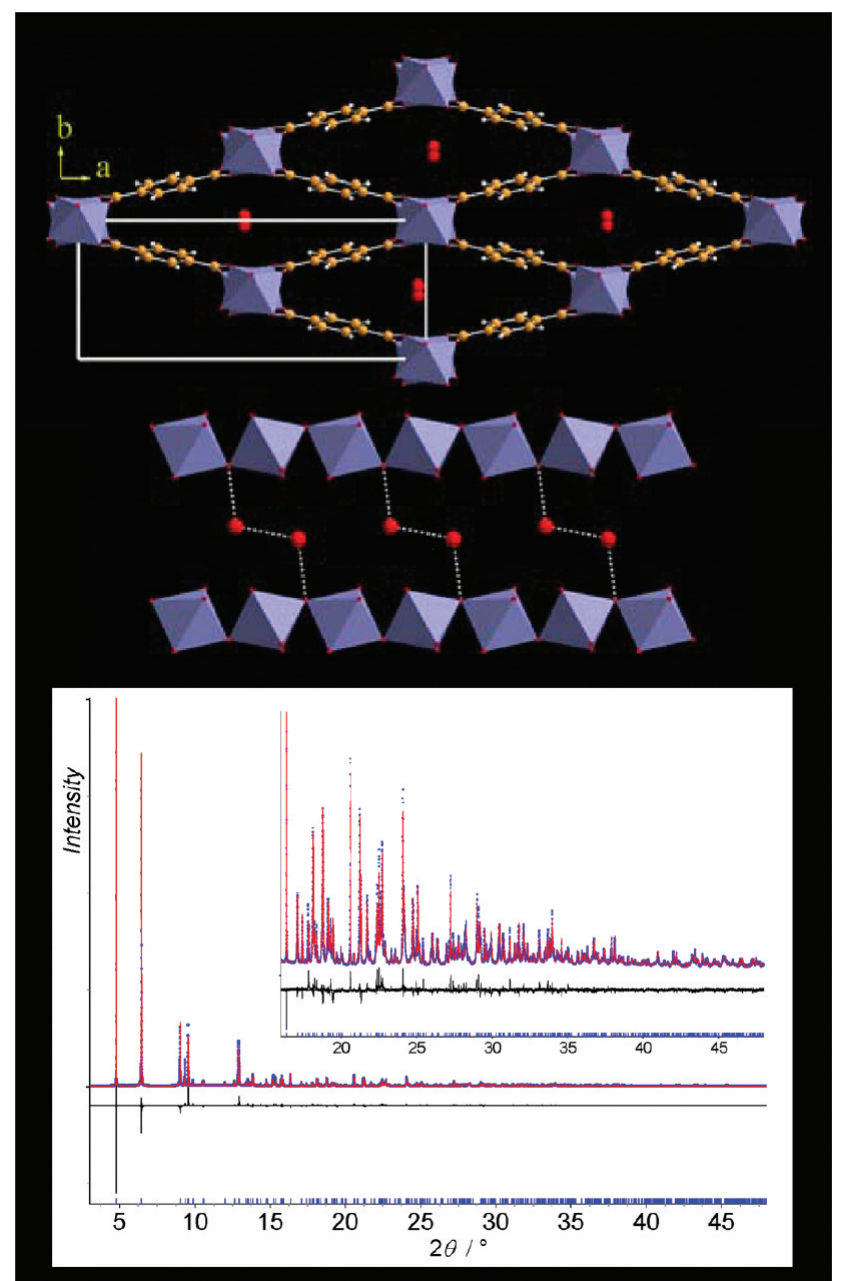

Figure 1. Two views of the structure of MIL-53(Fe) $\left[\mathrm{H}_{2} \mathrm{O}\right]$ (top) in the $a b$ plane showing oxygens of water molecules within the lozenge-shaped channels and (middle) in the $b c$ plane showing hydrogen bonding interactions (dotted lines) between water and framework oxygens. Final Rietveld plot (bottom) for MIL-53( $\mathrm{Fe})\left[\mathrm{H}_{2} \mathrm{O}\right]$ from X-ray powder diffraction data measured at room temperature. Blue points are experiment data, the red line is the fit, and the black line the difference curve. The tick marks are for the unit cell.

technological applications that require separation or exchange, and the cases of $\mathrm{CO}_{2}$ and $\mathrm{CH}_{4}$ are of great importance for environmental concerns. The MIL-53 structure is found for a variety of metals in the +3 oxidation state, including $\mathrm{Al}, \mathrm{Ga}, \mathrm{In}, \mathrm{V}, \mathrm{Cr}$, and $\mathrm{Fe}$, and it has already been noted that the choice of framework metal can affect the breathing properties of the materials. ${ }^{17}$ For example, when hydrated MIL-53(Cr) or 


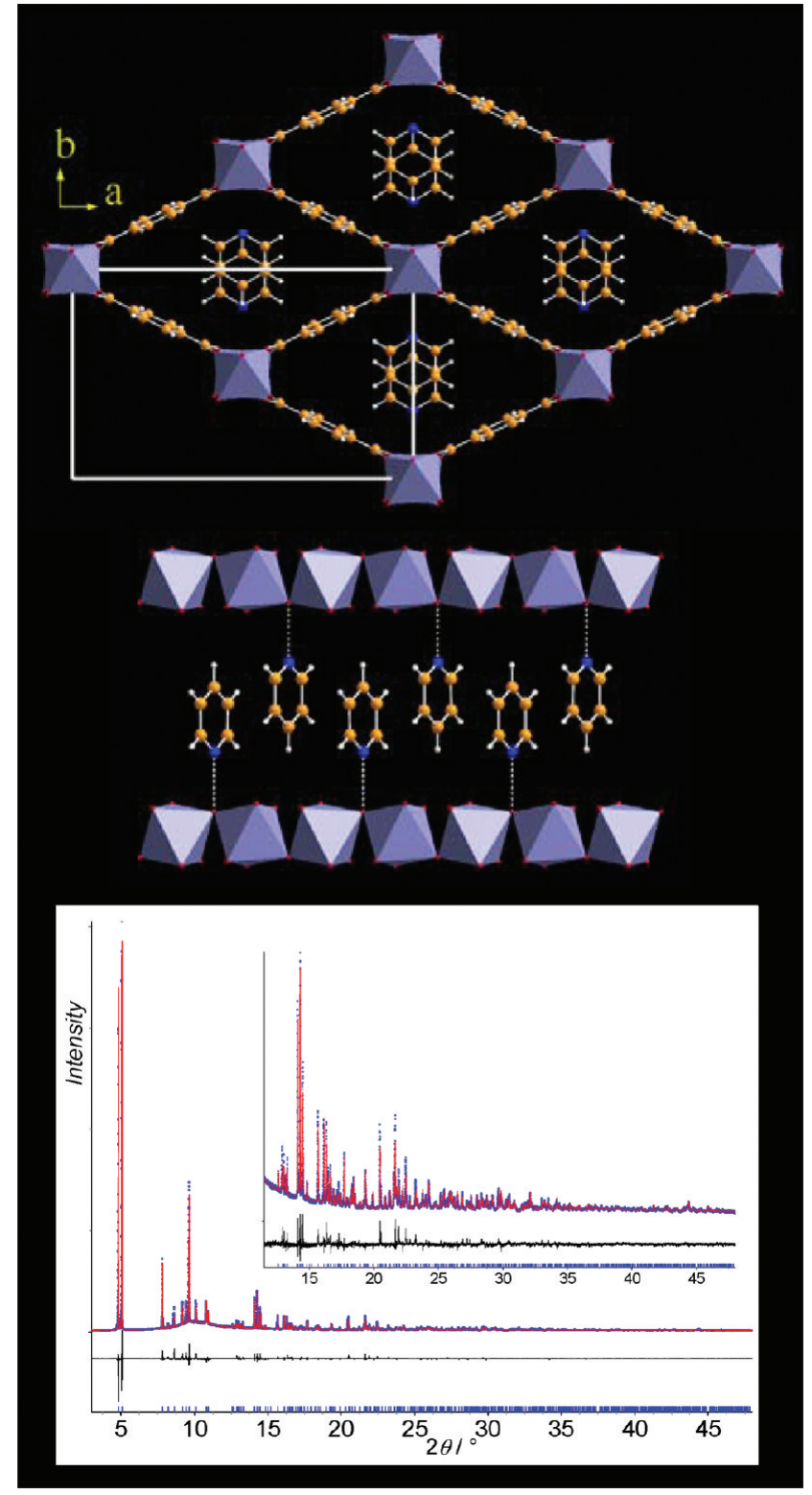

Figure 2. Two views of the structure of MIL-53(Fe)[pyridine] (top) in the $a b$ plane showing stacked pyridine molecules within the lozenge-shaped channels and (middle) in the $b c$ plane showing hydrogen bonding interactions (dotted lines) between pyridine $\mathrm{N}$ donor atoms and framework oxygens. Final Rietveld plot (bottom) for MIL-53(Fe)[pyridine] from $\mathrm{X}$-ray powder diffraction data measured at room temperature. Legend as for Figure 1.

MIL-53(Al) are heated they show a full structural opening upon water loss at $\sim 60^{\circ} \mathrm{C}$, MIL-53(Fe) shows little expansion, with pore volume associated with the closed form maintained on dehydration by heating to $150^{\circ} \mathrm{C}$, even via the formation of a metastable, intermediate dehydrated state, ${ }^{17}$ and MIL-53(Ga) shows an intermediate situation, with a closed, dehydrated form persisting until above $200{ }^{\circ} \mathrm{C}$ before the open form is produced. ${ }^{30}$ The expansion and contraction of the structure may not only be controlled by the presence of guest molecules, since temperature alone may have an influence; for example for MIL-53(Al), Liu et al. found that once dehydrated the

(30) Volkringer, C.; Loiseau, T.; Guillou, N.; Ferey, G.; Elkaim, E.; Vimont, A. Dalton Trans. 2009, 2241.

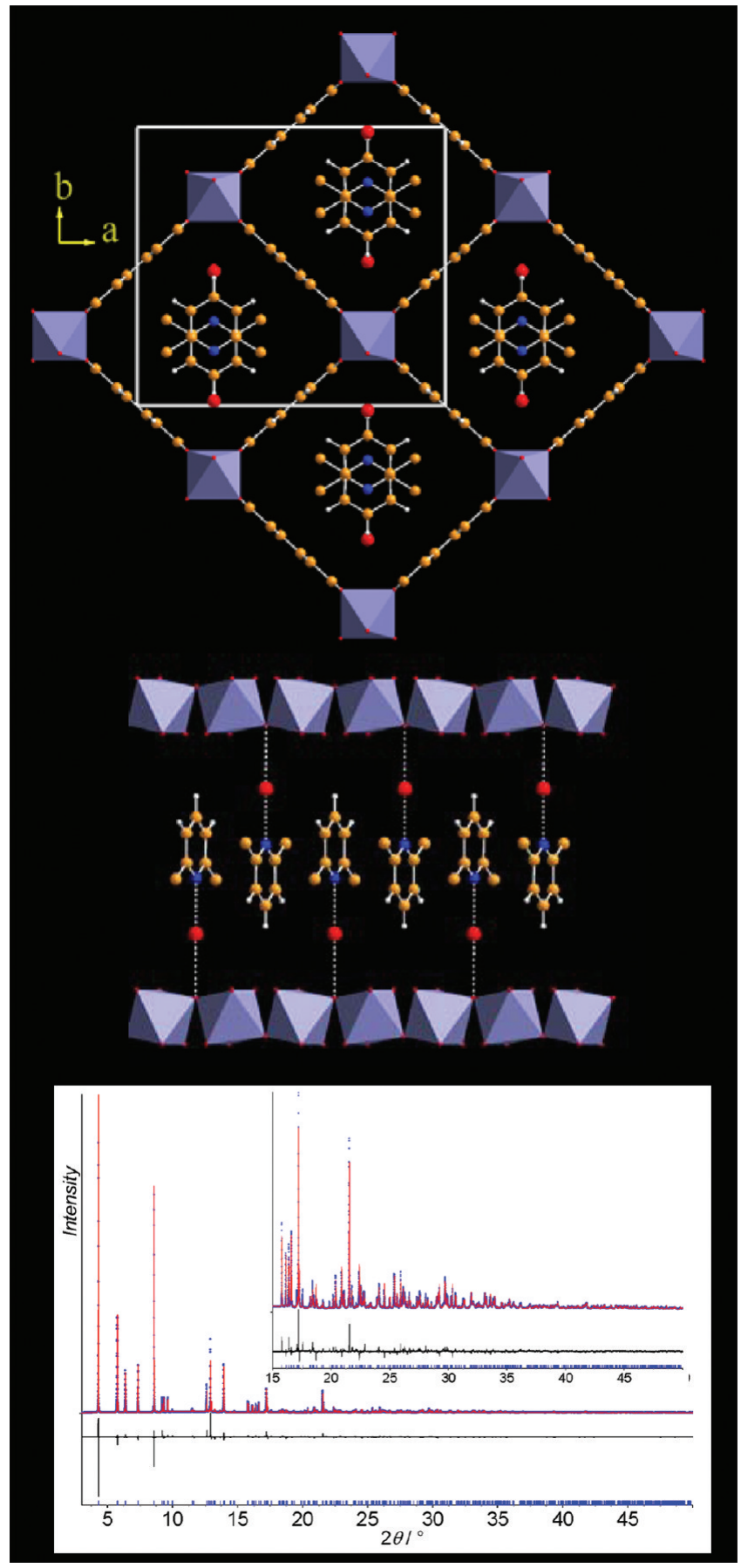

Figure 3. Two views of the structure of MIL-53(Fe)[lutidine, $\left.\mathrm{H}_{2} \mathrm{O}\right]$ (top) in the $a b$ plane showing stacked lutidine molecules and water molecules (oxygen atoms shown) within the lozenge-shaped channels and (middle) in the $b c$ plane showing hydrogen bonding interactions (dotted lines) between lutidine $\mathrm{N}$ donor atoms, water molecules and framework oxygens. Final Rietveld plot (bottom) for MIL-53(Fe)[2,6-lutidine, $\left.\mathrm{H}_{2} \mathrm{O}\right]$ from X-ray powder diffraction data measured at room temperature. Legend as for Figure 1.

material spontaneously contracts from the open to the closed form on cooling to $77 \mathrm{~K}$ and proposed that low energy librational motions of the benzene rings of the terephthalate linkers were responsible for the structural phase transitions. ${ }^{31}$

(31) Liu, Y.; Her, J. H.; Dailly, A.; Ramirez-Cuesta, A. J.; Neumann, D. A.; Brown, C. M. J. Am. Chem. Soc. 2008, 130, 11813. 


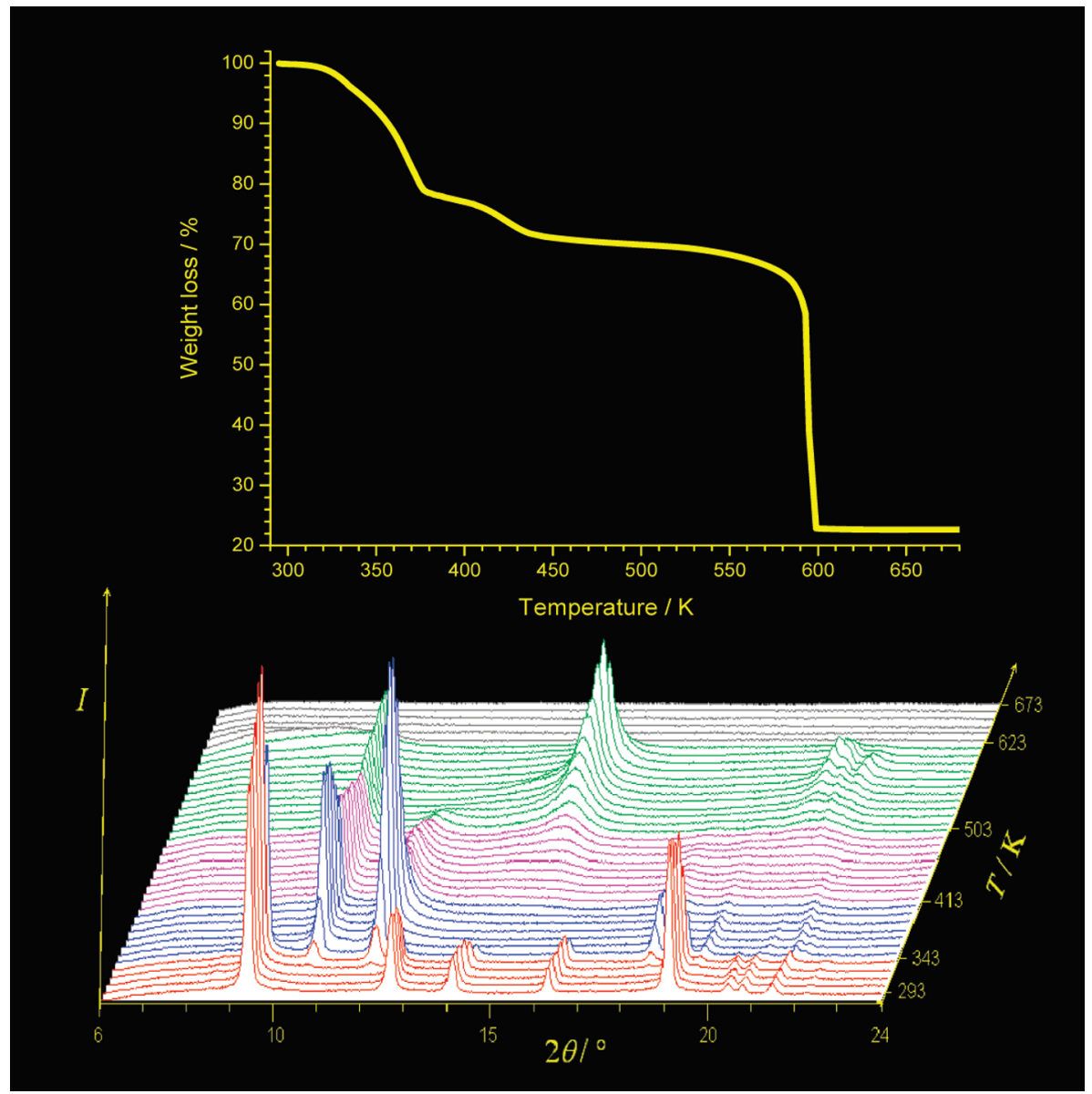

Figure 4. Thermal behavior of MIL-53(Fe)[lutidine, $\left.\mathrm{H}_{2} \mathrm{O}\right]$ (top) TGA trace and (bottom) thermodiffractometry measured from room temperature to $673 \mathrm{~K}$ (note that the wavelength $1=1.7903 \AA$ of the thermodiffractometry experiment is different from the data recorded in the high resolution structural study; see Experimental Section.).

Following our preliminary communication of an investigation of the uptake of a wide variety of liquid-phase organics by solid MIL-53(Fe), ${ }^{24}$ we now present a detailed study of one particular case involving two related molecules, pyridine and 2,6-lutidine (2,6-dimethylpyridine) in which different steric hindrances can greatly influence the nature and the strength of the guest interactions with the walls of the tunnels of the host. A detailed structural study of the solid host with these encapsulated guest molecules has allowed us to rationalize the interactions that stabilize the organics within the MOF, while time-resolved X-ray diffraction (XRD) reveals the steps involved in the selective uptake of one molecule over another in the liquid phase. This illustrates the use of the solid as a selective sorbent for organic molecules.

\section{Experimental Section}

Preparation of MIL-53( $\mathrm{Fe})\left[\mathrm{H}_{2} \mathrm{O}\right]$. MIL-53( $\left.\mathrm{Fe}\right)\left[\mathrm{H}_{2} \mathrm{O}\right]$ was solvothermally synthesized (autogenous pressure) from an equimolar amount of iron(III) chloride hexahydrate $\mathrm{FeCl}_{3} \cdot 6 \mathrm{H}_{2} \mathrm{O}$ (Aldrich, 97\%, $1 \mathrm{mmol}$ ), 1,4-benzenedicarboxylic acid $\mathrm{HO}_{2} \mathrm{C}$ $\left(\mathrm{C}_{6} \mathrm{H}_{4}\right)-\mathrm{CO}_{2} \mathrm{H}$ (Alfa, 97\%, $1 \mathrm{mmol}$ ), hydrofluoric acid $\mathrm{HF}$ (Prolabo, $5 \mathrm{M}, 1 \mathrm{mmol}$ ) in $N, N^{\prime}$-dimethylformamide (DMF, Aldrich $99 \%, 5 \mathrm{~mL}$ ). Reactants were stirred a few minutes before introducing the resulting suspension in a Teflon-lined steel autoclave. The sealed autoclave was placed in a preheated fan oven with the temperature set at $423 \mathrm{~K}$ and after 3 days removed while hot and allowed to cool in air to room temperature over a period of few hours. A light orange MIL-53(Fe)[DMF] powder was recovered by filtration and first washed with $\mathrm{MeOH}$ to obtain MIL-53(Fe) $[\mathrm{MeOH}]$ after complete exchange of DMF molecules by $\mathrm{MeOH}$. Finally, MIL-53( $\mathrm{Fe})\left[\mathrm{H}_{2} \mathrm{O}\right]$ was obtained after dispersion into water and drying in air. Quantitative elemental analyses (performed using ICP-MES for Fe, Schöniger flask combustion followed by titration for fluorine and by combustion analysis for CHN, by Medac Ltd., U.K.) gave the following results: Fe: $23.7 \%$; C: $35.6 \%$; $\mathrm{H}: 2.68 \%$ and $\mathrm{F}: 1.31 \%$ which compare well with those calculated from the formula $\mathrm{Fe}^{\mathrm{III}}(\mathrm{OH})_{0.8} \mathrm{~F}_{0.2}\left(\mathrm{O}_{2} \mathrm{C}-\right.$ $\left.\mathrm{C}_{6} \mathrm{H}_{4}-\mathrm{CO}_{2}\right) .\left(\mathrm{H}_{2} \mathrm{O}\right)$ : Fe: $21.9 \%$; C: $37.6 \%$; H: $2.68 \%$ and $\mathrm{F}$ : $1.48 \%$. The ratio of $\mathrm{F} / \mathrm{OH}$ in MIL-53(Fe) cannot be controlled by varying the amount of $\mathrm{HF}$, but the pure hydroxide phase can be prepared. ${ }^{17}$ To introduce organic guest molecules into MIL$53(\mathrm{Fe})\left[\mathrm{H}_{2} \mathrm{O}\right]$, the solid material $(\sim 0.4 \mathrm{~g})$ was stirred in $\sim 10 \mathrm{~cm}^{3}$ of the organic liquid overnight, and the product recovered by filtration and dried at room temperature in air. The behavior of the non-fluorinated material toward pyridine and 2,6-lutidine is identical: the materials produced have almost the same cell parameters and crystal symmetry.

High-Resolution Powder XRD. Powder XRD data were collected on ID31 of the European Synchrotron Radiation Facility from powdered samples contained in a $1 \mathrm{~mm}$ diameter quartz capillary. The beamline receives X-rays from the synchrotron source (which operates with an average energy of $6 \mathrm{GeV}$ and a 


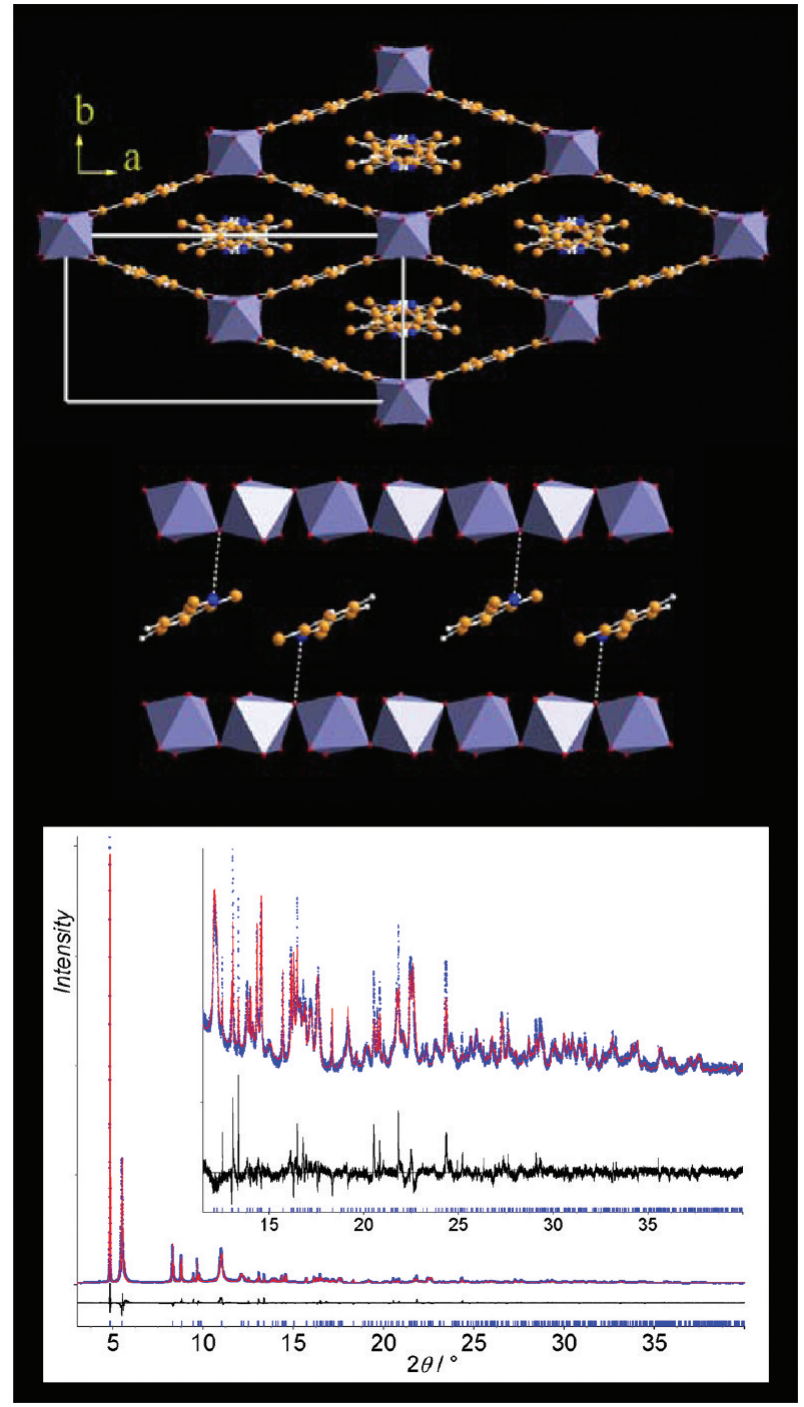

Figure 5. Two views of the structure of MIL-53(Fe)[lutidine ${ }_{0.5}$ ] (top) in the $a b$ plane showing stacked lutidine molecules within the lozengeshaped channels and (middle) in the $b c$ plane. Final Rietveld plot (bottom) for MIL-53(Fe)[lutidine ${ }_{0.5}$ ] from X-ray powder diffraction data measured at room temperature. Legend as for Figure 1.

current beam of typically $100 \mathrm{~mA}$ ) from an undulator device. The incident X-ray wavelength was $0.79989 \AA$ A with a beam size of $2.0 \mathrm{~mm}$ (horizontal) $\times 1.0 \mathrm{~mm}$ (vertical) used. For the cases where the interaction of samples with an organic guest was to be studied, the liquid solvent was injected into the capillary and the capillary then centrifuged to concentrate the solid to the end of sample holder; this minimized the background of the liquid and prevented the loss of solvent from the solid during the experiment. The samples were rapidly spun during data collection to ensure good powder averaging. Unit cells and space groups were found unambiguously with satisfactory figures of merit $\left[M_{20}=\right.$ 435 for MIL-53(Fe)[H $\left.\mathrm{H}_{2} \mathrm{O}\right], M_{20}=250$ for MIL-53(Fe)[pyridine], $M_{20}=744$ for MIL-53(Fe)[ 2,6-lutidine, $\mathrm{H}_{2} \mathrm{O}$ ], and $M_{20}=65$ for MIL-53(Fe)[2,6-lutidine 0.5 ] (see Table 1). For MIL-53(Fe) $\left[\mathrm{H}_{2} \mathrm{O}\right]$, the atomic coordinates of the MIL-53(Cr) skeleton ${ }^{15}$ were used as a starting model in the Rietveld refinement, and the position of the water molecule was redetermined by difference Fourier map calculations. For MIL-53(Fe)[pyridine], a related structure of hydroxylated iron(III) benzenedicarboxylate with occluded pyridine as determined by Whitfield et al. ${ }^{16}$ using single crystal XRD was used for the starting point of Rietveld refinement, and the pyridine molecule was treated as rigid body. For MIL-53(Fe)[ 2,6-lutidine, $\mathrm{H}_{2} \mathrm{O}$ ], first calculations were performed with the EXPO package, ${ }^{32}$ using EXTRA for extracting integrated intensities and SIR97 for direct methods structure solution. A list of 311 reflections was extracted in the angular range $4-40^{\circ}(2 \theta)$. According to the degree of diffraction overlap, $55.78 \%$ of these reflections were statistically considered as independent, and the whole structural model was found unambiguously from the E-map with the highest figure of merit. The atomic coordinates were then used as a starting model in the Rietveld refinement, and the 2,6lutidine molecule was treated as rigid body. For MIL-53(Fe)$\left[2,6\right.$-lutidine $\left.{ }_{0.5}\right]$, the atomic coordinates of the MIL-53(Fe)[pyridine] hybrid framework were used as a starting model in the Rietveld refinement. The half 2,6-lutidine molecule was localized by using a direct space approach based on simulated annealing using TOPAS. ${ }^{33}$ For all Rietveld refinements, terephthalate ions were treated as rigid bodies and anisotropic line broadening effects were corrected by using spherical harmonics series in TOPAS. The final Rietveld plots correspond to satisfactory crystal structure model indicators and profile factors (see Table 1).

Time-Resolved EDXRD Experiments. Time-resolved energy dispersive XRD (EDXRD) measurements were made on Beamline F3 of the HASYLAB facility (DESY, Hamburg, Germany). This beamline receives white-beam radiation with energy $13.5-65 \mathrm{keV}$, and the incident $\mathrm{X}$-ray beam is collimated to dimensions $20 \times 20 \mu \mathrm{m}^{2}$. Scattered X-rays were detected using a germanium solid-state detector positioned at $2.92^{\circ}(2 \theta)$, calibrated using the set of Bragg peaks measured from a pre-made, polycrystalline sample of MIL-53, and data accumulated in $60 \mathrm{~s}$ intervals. Data were measured from a rapidly stirred suspension of MIL-53 (400 mg) in $4 \mathrm{~mL}$ of water held within $1 \mathrm{~cm}$ diameter Pyrex tubes, with solutions of $10 \%$ pyridine in water, $10 \% 2$,6-lutidine in water or $5 \%$ pyridine-5\% 2,6-lutidine in water added dropwise via a syringe pump at $\sim 0.2 \mathrm{~mL}$ per hour. This controlled addition was necessary to monitor the temporal evolution of diffraction patterns: if the organic solutions were added in a single batch then the reaction reached completion within minutes, before the data collection commenced. Although this method prevents the acquisition of true kinetic data, it has previously been used successfully to observe the evolution of crystalline phases for solid-liquid reactions that happen on fast time-scales. ${ }^{34}$ In the EDXRD experiment the $d$-spacing $(d / \AA)$ of each characteristic Bragg peak is defined by energy $(E / \mathrm{keV})$, related to the fixed angle of the measuring position $(2 \theta)$ by eq 1 .

$$
d=\frac{6.1992}{E \sin \theta}
$$

Despite the inherent low energy (and hence $d$-spacing) resolution of the EDXRD method, because of the nature of the solidstate energy-discriminating detector, its advantage lies in the use of intense white X-rays that can penetrate laboratory-scale reactions vessels to acquire data rapidly from solid-liquid mixtures without problems that may be encountered on scaling

(32) Altomare, A.; Burla, M. C.; Camalli, M.; Carrozzini, B.; Cascarano, G. L.; Giacovazzo, C.; Guagliardi, A.; Moliterni, A. G. G.; Polidori, G.; Rizzi, R. J. Appl. Crystallogr. 1999, 32, 339.

(33) Topas V4.2; General Profile and Structure Analysis Software for Powder Diffraction Data; Bruker AXS Ltd: Madison, WI, 2004.

(34) O'Hare, D.; Evans, J. S. O.; Fogg, A.; O'Brien, S. Polyhedron 2000, $19,297$. 

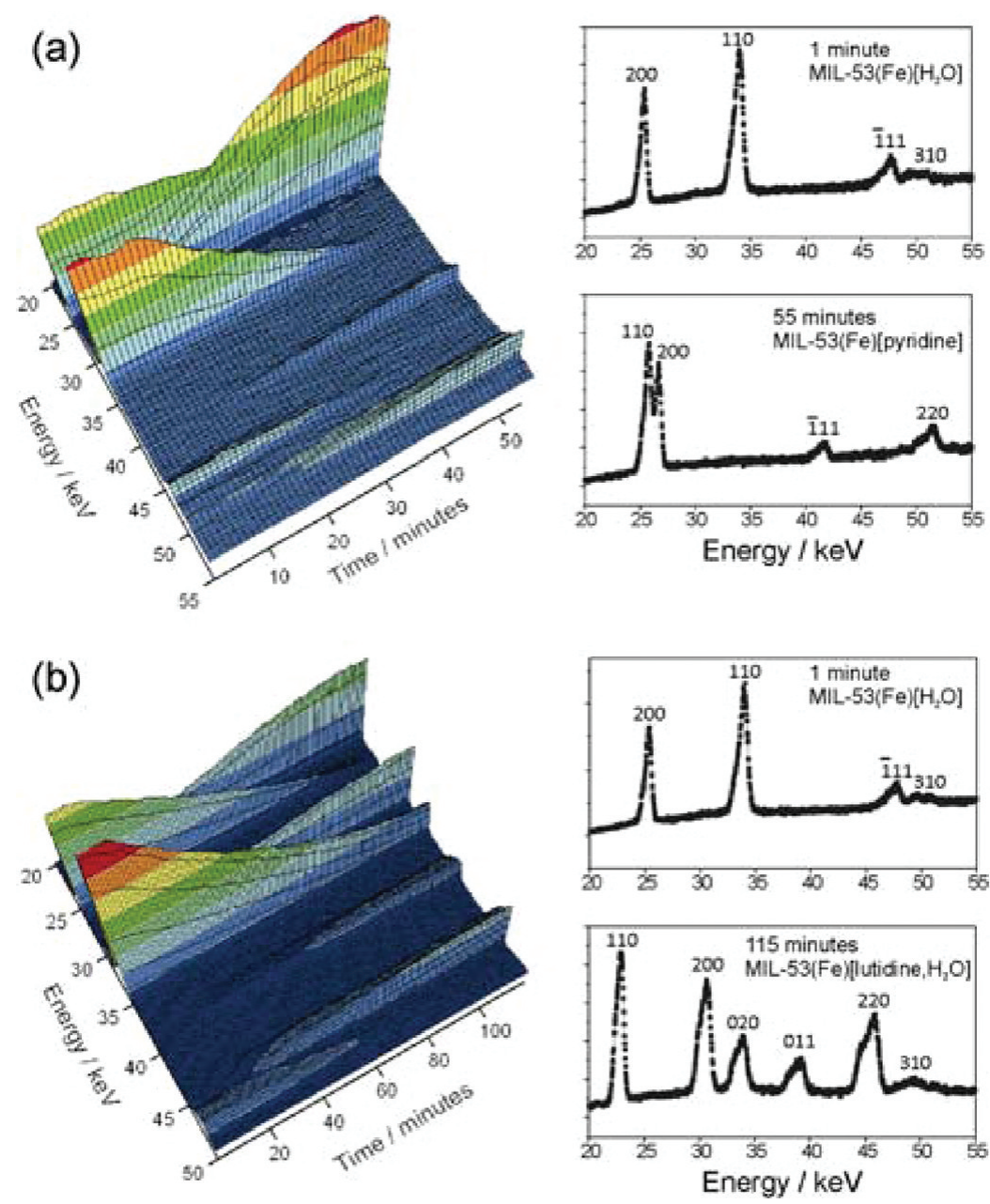

Figure 6. In situ EDXRD contour maps of (a) the uptake of pyridine ( $10 \%$ in water) by MIL-53( $\mathrm{Fe})\left[\mathrm{H}_{2} \mathrm{O}\right]$ and (b) the uptake of lutidine ( $10 \%$ in water) by MIL-53(Fe) $\left[\mathrm{H}_{2} \mathrm{O}\right]$. The panels on the right are EDXRD spectra at the beginning and end of the reactions with indexed Bragg peaks.

to small volumes. ${ }^{35-39}$ Raw EDXRD data were converted using the program PowDLL ${ }^{40}$ into a format suitable for reading into the program $\mathrm{XFIT}^{41}$ where peak fitting using PseudoVoigt functions was undertaken to determine Bragg peak areas with time to produce the extent of reaction curves.

HPLC Apparatus and Chromatographic Conditions. The apparatus used was a JASCO-HPLC-900 Series chromatograph system equipped with a PU-980 intelligent pump, a Mod. 975 UV-Visible detector and a Mod. 7125 Rheodyne injector with a $10 \mu \mathrm{L}$ external loop. The column was a Nucleodur $\mathrm{C} 18$ gravity $(125 \times 3.0 \mathrm{~mm}, 3 \mu \mathrm{m})$ operating at $30{ }^{\circ} \mathrm{C}$ with a column thermostat Jettream 2 plus. The elution was carried out under isocratic condition at a flow-rate of $0.5 \mathrm{~mL} \cdot \mathrm{min}^{-1}$. The mobile

(35) Walton, R. I.; Loiseau, T.; O'Hare, D.; Férey, G. Chem. Mater. 1999, 11, 3201 .

(36) Walton, R. I.; O'Hare, D. Chem. Commun. 2000, 2283.

(37) Kiebach, R.; Schaefer, M.; Porsch, F.; Bensch, W. Z. Anorg. Allg. Chem. 2005, 631, 369.

(38) Sankar, G.; Okubo, T.; Fan, W.; Meneau, F. Faraday Discuss. 2007, 136, 157.

(39) Kiebach, R.; Pienack, N.; Bensch, W.; Grunwaldt, J. D.; Michailovski, A.; Baiker, A.; Fox, T.; Zhou, Y.; Patzke, G. R. Chem. Mater. 2008, $20,3022$.

(40) Kourkoumelis, N. PowDLL, A program for the interconversion of powder diffraction data files, Version 2.19; 2009; http://users.uoi.gr/ nkourkou/powdll.htm.

(41) Cheary, R. W.; Coelho, A. A. XFIT; deposited in CCP14 Powder Diffraction Library, Engineering and Physical Sciences Research Council; Daresbury Laboratory, Warrington, England, 1996; http:// www.ccp14.ac.uk/. phase consisted of a solution of $0.05 \mathrm{M}$ phosphate bufferacetonitrile $70: 30$ by volume, adjusted to $\mathrm{pH} 8.0$. The detector was set at the wavelength of $254 \mathrm{~nm}$. Responses were recorded and integrated using ChromNav chromatographic software.

\section{Results and Discussion}

Structures of MIL-53(Fe)[Guest] Materials. The structure of the MIL-53( $\mathrm{Fe})\left[\mathrm{H}_{2} \mathrm{O}\right]$ material has been described previously as a pure $\mathrm{OH}$ version. ${ }^{17}$ In the fluorinated version of material we have studied here, $\mathrm{Fe}^{\mathrm{III}}(\mathrm{OH}, \mathrm{F})$ $\left\{\mathrm{O}_{2} \mathrm{C}-\mathrm{C}_{6} \mathrm{H}_{4}-\mathrm{CO}_{2}\right\} \cdot \mathrm{H}_{2} \mathrm{O}$, the MIL-53 framework is also in its "closed" form (see Table 1), but the arrangement of the guest water molecules does not lead to a superstructure and only one type of channel is observed, showing the influence of the presence of some fluoride ions. As shown by Figure 1, there are hydrogen bonding interactions (i) between water molecules and the framework hydroxide ions that bridge the $\mathrm{Fe}$ (III) centers that form the backbone of the infinite inorganic chains running parallel to $c$ and (ii) between guest water molecules located in lozengeshaped channels running parallel to the inorganic chains. The closest $\mathrm{O}-\mathrm{-O}$ contacts provide clear evidence for the presence of two types of hydrogen bonds: $\mathrm{O} 1-\mathrm{Ow} 1=$ $2.746(5) \AA$ between guest water and the framework and Ow $1-O w 1=2.865(9) \AA$ leading to water dimerization. 

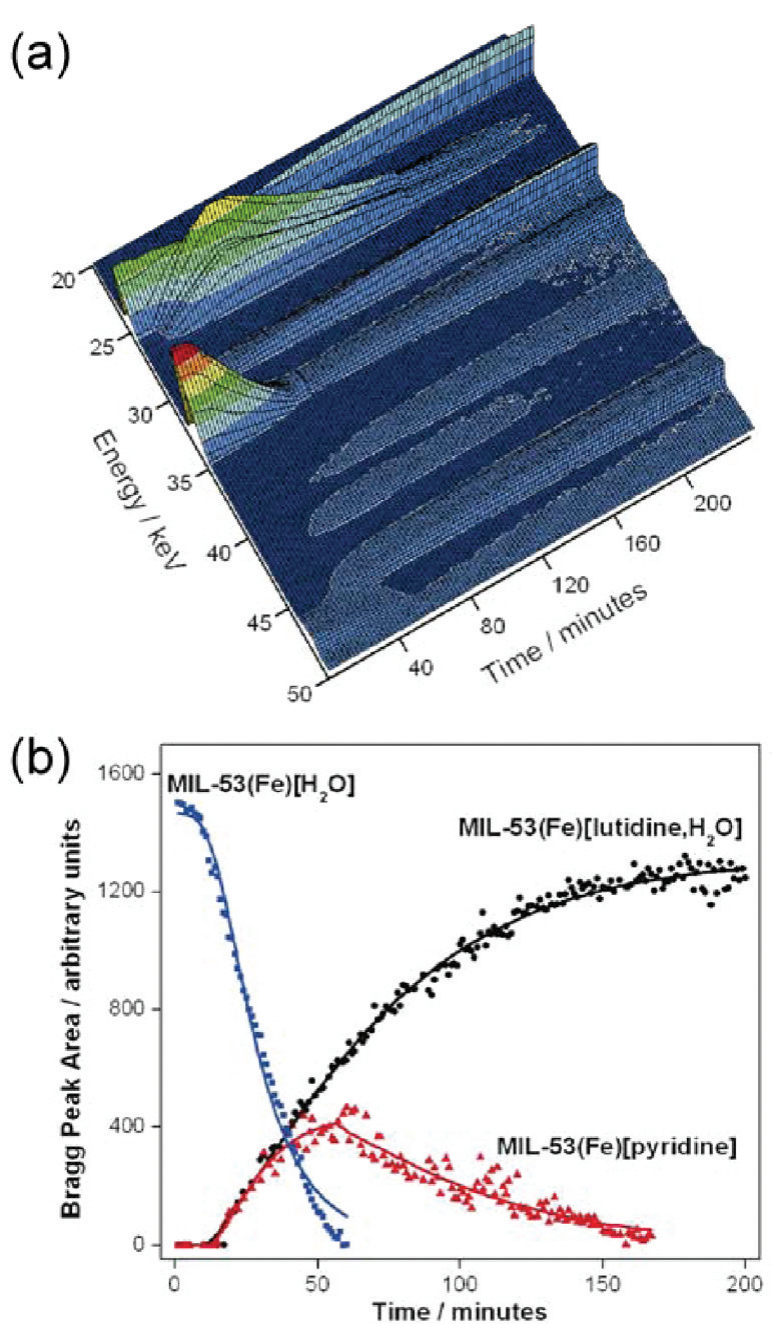

Figure 7. (a) In situ EDXRD contour map showing the reaction between MIL-53( $\mathrm{Fe})\left[\mathrm{H}_{2} \mathrm{O}\right]$ and a $5 \%$ pyridine $-5 \%$ lutidine solution in water (b) Extent of reaction curves derived by integration of Bragg peaks using the MIL-53(Fe)[H $\left.\mathrm{H}_{2} \mathrm{O}\right] 110$ peak at $\sim 34 \mathrm{keV}$, the MIL-53(Fe)[pyridine] $\overline{1} 11$ peak at $\sim 41 \mathrm{keV}$, and the MIL-53(Fe)[lutidine, $\mathrm{H}_{2} \mathrm{O}$ ] 110 peak at $\sim 22 \mathrm{keV}$.

Upon introduction of pyridine the MIL-53 structure expands (Table 1) and as shown in Figure 2 the guest molecules are stacked face-to-face but have opposite orientations, that is, a head-to-tail arrangement, in such a way as to allow hydrogen bonding between pyridine $\mathrm{N}$ donors and the framework $(\mathrm{N} 1-\mathrm{O} 1=2.630(4) \AA)$. The $\mathrm{N} 1 \cdots \mathrm{C} 4$ axis of the pyridine ring is perpendicular to the octahedral chains. The orientation of the pyridine ring is probably a result of a compromise between geometric requirements of the $\mathrm{N} 1 \cdots \mathrm{H}-\mathrm{O} 1$ hydrogen bonds and $\pi-\pi$ interactions between neighboring pyridine rings (ring $\cdots$ ring distance: $3.47 \AA$ ). Thermogravimetric analysis (TGA; Supporting Information) of the MIL-53(Fe)[pyridine] material shows clear evidence for a single-step loss of organics up to $450 \mathrm{~K}$. However, thermodiffractometry (Supporting Information) shows some evidence for the presence of a new phase between 363 and $423 \mathrm{~K}$, but this poorly ordered phase, which could be due to partial loss of the pyridine guest, can not be indexed.

When MIL-53(Fe) $\left[\mathrm{H}_{2} \mathrm{O}\right]$ is immersed in 2,6-lutidine, structure solution and refinement, Figure 3, reveal that the material formed contains both 2,6-lutidine and water within the pores of the structure. The MIL-53 framework is now in its fully open, expanded form, and the location of the water molecules is such that they provide a means for bridging between the 2,6-lutidine N-donor and the framework hydroxide groups via hydrogen bonding $(\mathrm{N} 1-\mathrm{Ow} 1=2.595(4) \AA$ and $\mathrm{Ow} 1-\mathrm{O} 1=2.956(6) \AA)$. We suggest that the steric effects of the methyl substituents prevent direct hydrogen bonding between the guest and host, hence co-sorption of water provides a way of giving a strong interaction between the organic guest and the framework. Neighboring 2,6-lutidine molecules are parallel to each other but have opposite orientations. The Ow $1 \cdots \mathrm{N} 1 \cdots \mathrm{C} 4$ axis is perpendicular to the octahedral chains. Here, co-sorption is also a compromise between geometric requirements of the $\mathrm{N} 1 \cdots \mathrm{Ow} 1 \cdots \mathrm{H}-\mathrm{O} 1$ hydrogen bonds and $\pi-\pi$ interactions between neighboring 2,6-lutidine rings (ring $\cdots$ ring distance: $3.47 \AA$ ).

Upon heating, the MIL-53(Fe)[2,6-lutidine, $\left.\mathrm{H}_{2} \mathrm{O}\right]$, decomposes in a complex manner as revealed by TGA (Figure 4). The first step, $\sim 5 \%$ mass to $350 \mathrm{~K}$, corresponds to a mass reduction that matches loss of just the occluded water, and this is then followed by sequential loss of various amounts of 2,6-lutidine (Supporting Information). Thermodiffractometry of MIL-53(Fe)[2,6lutidine, $\mathrm{H}_{2} \mathrm{O}$ ] shows that crystallinity is maintained for several of these steps. This information allowed us to isolate one of the intermediate phases, MIL-53(Fe)[2,6lutidine $\left._{0.5}\right]$, in a crystalline form for structure solution and refinement. This material is anhydrous with an intermediate pore opening reflected in the unit cell volume that is close to that seen for the pyridine phase. The orientation of the guest molecules, Figure 5, reflects the fact that hydrogen bonding between 2,6-lutidine and the framework $\mathrm{OH}$ groups is not possible because of the steric interference of the methyl substituents. Here both the host-guest and guest-guest interactions must be considerably weaker (the $\mathrm{N} 1-\mathrm{O} 1$ distance are all greater than $3 \AA$ while the shortest distance between neighboring 2,6lutidine rings is $4.1 \AA$ ) so we speculate that the guest molecules have largely a space-filling role. Interestingly, once water has been removed by heating the MIL-53(Fe)[2,6-lutidine, $\mathrm{H}_{2} \mathrm{O}$ ] material, the process is irreversible: in situ XRD shows that on heating and cooling in moist air the material MIL-53(Fe)[2,6-lutidine $\left.{ }_{0.5}\right]$ maintains its structure (Supporting Information).

Time-Resolved Diffraction Study of Sorption of Organics. Figure 6 shows contour maps of in situ EDXRD data measured during the uptake (separately) of pyridine and 2,6-lutidine by MIL-53(Fe) $\left[\mathrm{H}_{2} \mathrm{O}\right]$. The only two phases present during each of the processes are the "closed" starting material and the "open" final product: Bragg peaks only due to the phases shown in Table 1 are present and there is no evidence for any intermediate open states. Thus the pore opening occurs in a stepwise fashion, crystal by crystal, at least on the time-scale of the measurement we make. An alternative mechanism is that of dissolution followed by recrystallization in the presence of the new guest: although this has previously been seen 

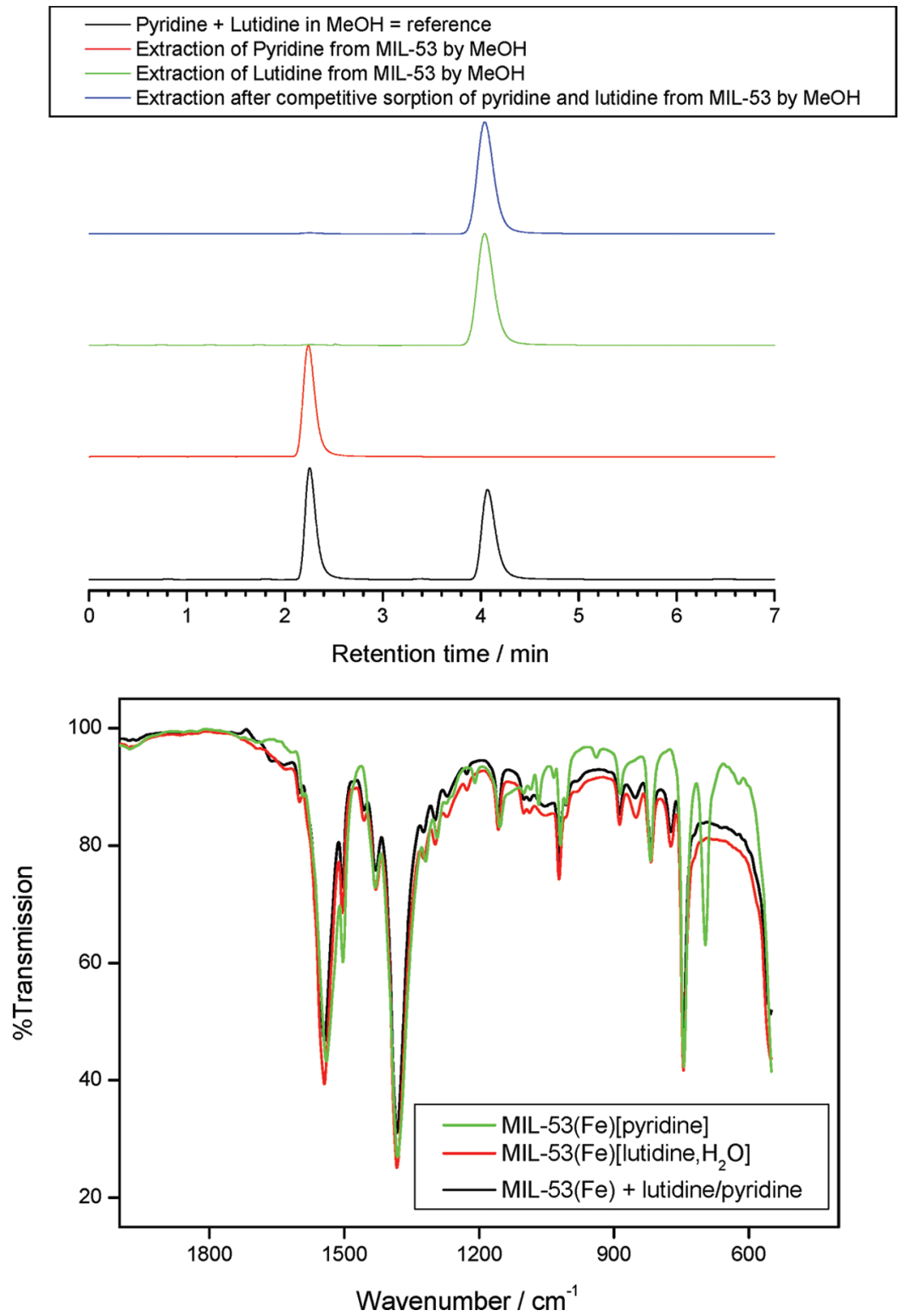

Figure 8. Evidence for separation of pyridine and lutidine by MIL-53(Fe): (top) HPLC plot of the solution produced by washing the solid product with excess water showing the presence of only lutidine. (bottom) IR of the solid product compared to MIL-53(Fe)[lutidine, $\left.\mathrm{H}_{2} \mathrm{O}\right]$ and MIL$53(\mathrm{Fe})[$ pyridine].

for Group 12 metal coordination polymers that have anionic guests, ${ }^{42}$ for MIL-53(Fe), where the guest molecules are neutral, this process is rather unlikely since the material has established flexibility in the gas phase where no solvent is required, ${ }^{17,25}$ the decay and growth in solution crosses at $\sim 50 \%$, and the solid shows high stability in a range of organic solvents with no sign of dissolution. ${ }^{24}$ Figure 7 a shows the case when a dilute aqueous solution containing a mixture of pyridine $(5 \%)$ and 2,6-lutidine $(5 \%)$ is added to MIL-53(Fe) $\left[\mathrm{H}_{2} \mathrm{O}\right]$. A close examination of the EDXRD spectra shows that initially the Bragg peaks of both the MIL-53(Fe)[pyridine] and the MIL$53(\mathrm{Fe})\left[2,6\right.$-lutidine, $\left.\mathrm{H}_{2} \mathrm{O}\right]$ phases replace those of the MIL$53(\mathrm{Fe})\left[\mathrm{H}_{2} \mathrm{O}\right]$ starting phase before ultimately the peak

(42) Cui, X. J.; Khlobystov, A. N.; Chen, X. Y.; Marsh, D. H.; Blake, A. J.; Lewis, W.; Champness, N. R.; Roberts, C. J.; Schroder, M. Chem.-Eur. J. 2009, 15, 8861. positions of the MIL-53(Fe)[2,6-lutidine, $\mathrm{H}_{2} \mathrm{O}$ ] material are the only ones present. Despite overlapping Bragg peaks of the three phases, integration of these representative reflections proved possible, and, as shown in Figure 7b, this allows the temporal evolution of the system to be traced, confirming the initial, simultaneous appearance of two phases. This also reveals that once the starting material is consumed, the MIL-53(Fe)[pyridine] then is replaced by solely MIL-53(Fe)[2,6-lutidine, $\left.\mathrm{H}_{2} \mathrm{O}\right]$. This assignment is based upon indexing the sets of Bragg peaks that are observed at each stage of reaction. To confirm that the final product contains 2,6-lutidine and not pyridine we performed two experiments: first, the solid product isolated after leaving MIL-53( $\mathrm{Fe})\left[\mathrm{H}_{2} \mathrm{O}\right]$ in a mixture of $50 \%$ pyridine- $50 \%$ 2,6-lutidine overnight was washed with a large excess of water to release the guest molecules, and the resulting solution was examined by HPLC (Figure 8a), 
and second IR spectroscopy of the solid product (Figure 8b) was compared with the reference IR of both MIL-53(Fe)[pyridine] and MIL-53(Fe)[2,6-lutidine, $\mathrm{H}_{2} \mathrm{O}$ ]. Both experiments unambiguously prove that the final product is MIL-53(Fe)[2,6-lutidine, $\left.\mathrm{H}_{2} \mathrm{O}\right]$. The final product is the most open form of the solid in which water molecules allow a hydrogen bonding interaction between the framework and the guest molecules. Thus although the MIL$53(\mathrm{Fe})\left[\mathrm{H}_{2} \mathrm{O}\right]$ host phase takes up pyridine and 2,6-lutidine easily (in the former case displacing water), the pyridine is subsequently replaced by 2,6-lutidine with co-sorption of water. Similar separation behavior has been reported for layered double hydroxides in the presence of a solution of carboxylate anions: when exposed to a mixture of two anions the initial rapid uptake of both takes place before the sole product containing one anion is formed with expulsion of the other. ${ }^{43,44}$ Studies of the separation of both the gas phase and the liquid phase separation of xylene (and other aromatic) isomers by materials with the MIL-53 structure have recently been reported by other groups. For example, Alaerts et al. showed that MIL53(Al) would preferentially bind ortho-isomers of xylene, ethyltoluene, and so forth in liquid phase separations, and rationalized the selectivity as arising from strong interactions between methyl groups of the sorbates and carboxylate moieties in the pore corners. ${ }^{23}$ It is difficult to compare that case directly with the organics we have studied since there was no scope for hydrogen bonding and all of the isomers of xylene interacting with the host give the fully open form of the structure. Clearly the balance of host - guest interactions stabilizing one phase over another is a subtle one, and guest-guest interactions are also important to consider, and indeed the choice of framework metal, which is known to give different breathing properties. ${ }^{17,30}$

(43) Fogg, A. M.; Dunn, J. S.; Shyu, S. G.; Cary, D. R.; O’Hare, D. Chem. Mater. 1998, 10, 351.

(44) Millange, F.; Walton, R. I.; Lei, L. X.; O'Hare, D. Chem. Mater. 2000, 12, 1990.

\section{Conclusions}

The structures of a series of MOFs containing organic guest molecules reveals the nature of host-guest interactions that may stabilize the flexible host structure in various open states. The nature of host-guest interaction is strongly controlled by the sterics of the organic guests: pyridine is able to form hydrogen bonds directly with framework hydroxides and can displace water to form a partially opened form of the MIL-53 structure, whereas in the case of 2,6-lutidine, the presence of methyl substituent means that water must be co-sorbed to allow hydrogen binding interactions and then a fully open form of MIL53 is produced. The flexible porous host MIL-53 is then able to act as selective sorbent of one organic guest over another to yield ultimately the most open form of the solid: in situ diffraction reveals that this separation occurs via an initial rapid uptake of two guest molecules (in separate phases) before one is replaced by the another. This suggests the distinct possibility of the use of the material for the liquid-phase separation of complex mixtures of structurally diverse organics under ambient conditions; this is something we are currently investigating.

Acknowledgment. We thank the ESRF for provision of beamtime on ID31, where we are grateful for the assistance of Dr I. Margiolaki and Dr. A. Fitch, and DESY for access to Beamline F3 at HASYLAB. This work was supported by CNRS and French ANR "CONDMOFs" funding. Some of the equipment used in materials characterization at the University of Warwick was obtained through the Science City Advanced Materials project "Creating and Characterising Next Generation Advanced Materials" with support from Advantage West Midlands (AWM) and part funded by the European Regional Development Fund (ERDF).

Supporting Information Available: Crystallographic data in CIF format and figures with the TGA trace, IR spectrum, and thermodiffractometry for MIL-53(Fe)[pyridine] and MIL-53(Fe)[lutidine, $\mathrm{H}_{2} \mathrm{O}$ ], respectively. This material is available free of charge via the Internet at http://pubs.acs.org. 